Original

\title{
New Estimation Methods of Bacterial Concentration by Measuring ATP Changes during Incubation
}

(Received December 17, 2001)

\author{
Hiroshi FujiKawA ${ }^{\dagger}$ and Satoshi Morozumi
}

(Tokyo Metropolitan Research Laboratory of Public Health: 3-24-1, Hyakunin-cho, Shinjuku-ku, Tokyo 169-0073, Japan; ${ }^{\dagger}$ Corresponding author)

\begin{abstract}
New estimation methods of bacterial cell concentration in samples by measurement of the increase in bacterial adenosine-triphosphate (ATP) content during incubation using a conventional firefly luminometer were established. When an Escherichia coli cell suspension was incubated in nutrient broth, the increase in the ATP content of the suspension during the incubation period followed a sigmoidal curve. The increase ratio of the ATP content of the suspension at a given period of incubation ( 5 hours in this study) to the initial ATP content was greater at higher initial cell concentrations. With this relationship, the initial cell concentration of a test suspension could be predicted from the measured ratio; this was called the end point method. On the other hand, the lag period in the ATP increase curve was longer at lower initial cell concentrations. A highly linear relationship was observed between the lag period and the logarithm of the initial cell concentrations. Based on this relationship, a delay method was developed for prediction. The two relationships were also observed for bacterial suspensions of Klebsiella sp., Staphylococcus aureus, Bacillus subtilis, and Pseudomonas sp. These results suggested that the two methods have the potential to estimate the bacterial cell concentration of a sample suspension.
\end{abstract}

Key words: ATP; bacterial cell concentration; luminometer; kinetics; end point method; delay method

\section{Introduction}

Measurement of microbial cell concentration in food materials, food products, and swabs of surfaces of food processing equipment is indispensable for evaluating the microbial contamination of the products. The most widely used, traditional method for measurement of bacterial cell concentration is the standard plate count method $^{1) 2}$. This method, however, requires a long incubation period of 48 hours $^{1), 2}$. When food products are shipped out of factories, the producers should know the level of microbial contamination of the products. At present, however, the products are often shipped before microbiological examination, which is time-consuming, yields a result. Therefore, rapid microbial examination methods are urgently needed in the food industry.

Among the methods available for measurement of microbial contamination, the firefly bioluminescence assay for adenosine triphosphate (ATP) is rapid and simple $^{3), 4)}$. A number of investigators have reported the use of this method for detection of microbial contamination in foods ${ }^{5-10)}$. This method, however, has one universal problem ${ }^{11,12)}$. That is, interference from large amounts of non-microbial ATP in foods. Some food samples show high ATP concentrations in comparison with their low microbial cell counts. This phenomenon can also be observed for swab samples of food processing instruments ${ }^{13)}$. A possible explanation is that food samples can contain high concentrations of endogenous ATP, because most food materials are of animal or plant origin and may retain their original ATP content ${ }^{14)}$.

Two solutions to the problem have been considered. One is the enzymatic destruction of non-microbial ATP in samples with ATPase. After the destruction of nonmicrobial ATP in food samples by the enzyme, the enzyme itself must be removed to avoid destruction of microbial ATP in the subsequent steps. This is done generally by washing the enzyme away on membrane filters with washing buffer ${ }^{15)}$. Another way is to separate the microbial cells from food materials in samples by centrifugation, followed by filtration through membranes ${ }^{16}$. In both procedures, the samples need to pass through conventional membrane filters with a pore size of 0.45 or $0.22 \mu \mathrm{m}^{15), 16)}$. Unfortunately, most solid processed food products and their homogenates in buffered saline can not pass through such filter membranes or be washed on the membranes with the buffer; the homogenates or the buffer stick on the membranes during the process. Thus, the application of the two methods to foods is strictly limited. As far as we know, the solid foods to which these methods can be applied for ATP measurement are raw vegetables and meat whose homogenates can pass through the filter membranes ${ }^{5), 6), 8), 10), 15), 16)}$. These methods cannot easily be applied to most processed, commercial foods for which we routinely need to measure their bacterial cell 
concentrations. At present, therefore, the ATP measurement of swab samples, which is the sum of ATP of food residues and microbial origins, is the major current application of bioluminescence assay of ATP, for the estimation of surface cleanliness, not of microbial contamination $^{4), 17)}$.

In these circumstances, we developed new, kinetic ATP measurement methods for bacterial cell counts in samples with a conventional firefly luminometer in this study. The methods were an end point method and a delay method. These methods are based on the increase kinetics of the ATP content in bacterial cells that proliferate in culture medium during incubation. With these methods, test samples do not need to pass through the filter membranes described above. In this study, we developed the new methods for measurement of bacterial cell concentration in cell suspension samples using bioluminescence assay.

\section{Materials and Methods}

\section{Bacterial cell preparation}

Bacterial strains of Escherichia coli, Klebsiella sp., Staphylococcus aureus, Bacillus subtilis, and Pseudomonas sp. were isolated from foods in our laboratory. Bacterial strains were cultured on nutrient agar plates at $35^{\circ} \mathrm{C}$ for 24 hours. Cells grown on the plates were cultured in 5 $\mathrm{mL}$ of nutrient broth (Nissui Pharmaceuticals, Tokyo, Japan) with shaking at $160 \mathrm{rpm}$ and $35^{\circ} \mathrm{C}$ for 24 hours. Cultured cells were washed twice with $0.1 \mathrm{~mol} / \mathrm{L}$ phosphate $-0.05 \mathrm{~mol} / \mathrm{L}$ citrate buffer, $\mathrm{pH} 7.0$ with $0.005 \%$ (vol/vol) Tween 80 by centrifugation at $6,200 \times g$ and $10^{\circ} \mathrm{C}$ for $15 \mathrm{~min}$. Cells were finally suspended in $5 \mathrm{~mL}$ of saline $(0.85 \% \mathrm{wt} / \mathrm{vol} \mathrm{NaCl}$ solution). The cell concentrations of the resultant suspensions were $10^{9} \mathrm{CFU} / \mathrm{mL}$. Portions $(5 \mathrm{~mL})$ of cell suspensions that were serially 10 -fold diluted with the saline were inoculated into 45 $\mathrm{mL}$ of nutrient broth preheated at $35^{\circ} \mathrm{C}$ in $100-\mathrm{mL}$ glass tubes with screw caps.

In a preliminary study, several culture media were compared for the kinetic methods using the $E$. coli strain. The media tested were nutrient broth (Nissui), brain heart infusion (Becton Dickinson, Sparks, U.S.A.), and trypticase soy broth (Becton Dickinson). There were no marked differences among the media in the ATP increase during incubation, although a slightly faster increase in ATP was observed in the nutrient broth. Thus, this medium was chosen for study.

\section{Incubation}

Bacterial cell suspensions in glass tubes prepared above were cultured with shaking at $120 \mathrm{rpm}$ at $35^{\circ} \mathrm{C}$. The temperature was that for the plate count method in our routine ${ }^{1,2)}$. At one-hour intervals during incubation, portions (about $3 \mathrm{~mL}$ ) of the samples were taken and cooled in ice water.

\section{ATP measurement}

ATP contents in bacterial cell suspensions were measured by the firefly luciferin-luciferase method with an ATP analyzer (AF-100, TOA Electronics, Tokyo) according to the manufacturer's technical manual. Briefly, portions $(100 \mu \mathrm{L})$ of samples were mixed with $100 \mu \mathrm{L}$ of an extract reagent (TOA) for $30 \mathrm{sec}$ to destroy bacterial cell walls. The samples were mixed with 200 $\mu \mathrm{L}$ of firefly luciferin-luciferase reagent (TOA) for 10 sec, then the luminescence was measured for the following $30 \mathrm{sec}$. The controls were ATP-free purified water (TOA) and $1.0 \mathrm{nmol} / \mathrm{L} \mathrm{ATP} \mathrm{solution} \mathrm{(TOA).}$

\section{Viable cell counts}

Viable cell counts of samples were measured with the standard plate count method ${ }^{1)}$, ; ten-fold dilutions of the samples with the buffered sodium chloride peptone solution were mixed with standard plate agar (Eiken Chemicals, Tokyo) and incubated at $35^{\circ} \mathrm{C}$ for 48 hours.

\section{Data analysis}

The increase kinetics of ATP contents in samples was analyzed in terms of the ratio of $A / A_{0}$. Here, $A$ is the ATP concentration measured $(\mathrm{nmol} / \mathrm{L})$ at an incubation time $t$ (hour) and $A_{0}$ is that at time zero. The numeral analyses were done with Microsoft Excel 2000.

\section{Results}

\section{Stability of ATP measurement}

Stability of ATP measurement with the analyzer was estimated using an E. coli cell suspension. When the ATP content of the bacterial suspension prepared at a cell concentration of $1.0 \times 10^{6} \mathrm{CFU} / \mathrm{mL}$ was measured 7 times, the measured values were essentially the same: $1.46,1.45,1.42,1.44,1.43,1.49$, and $1.46 \mathrm{nmol} / \mathrm{L}$. The average and standard deviation of the values were 1.45 and $0.0231 \mathrm{nmol} / \mathrm{L}$, respectively. The coefficient of variation was very small, being $1.59 \%$. This low variability of ATP measurement led us to conclude that two ATP measurements with the analyzer could be enough for each sample. Thus, ATP measurement was subsequently done twice per sample in this study.

\section{ATP increase during E. coli growth}

The increase in the ATP content of $E$. coli cell suspensions cultured in nutrient broth was studied at various initial cell concentrations of $10^{1}-10^{5} \mathrm{CFU} / \mathrm{mL}$. The increase curves of the ATP content of the cell suspensions consisted of a lag period, a linear increase period, and a decelerating or stationary period (for example, Fig. 1 shows a curve for the initial concentration of $10^{5}$ $\mathrm{CFU} / \mathrm{mL})$.

\section{End point method}

From the increase ratio in the ATP content of a sample suspension incubated for a given period, the initial cell concentration could be estimated; this was called the end point method. The increase kinetics of the ATP content at various initial cell concentrations shown in Fig. 1 was analyzed for various incubation periods (Fig. 2). At a short incubation period such as 2 hours, the increase ratios at low initial cell concentra- 


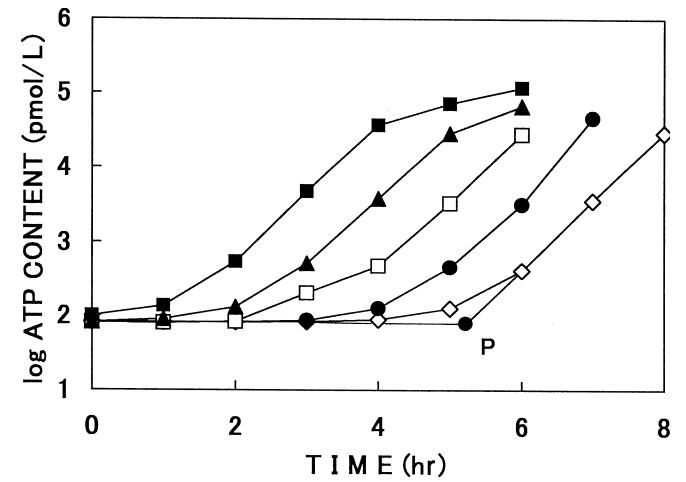

Fig. 1. Increase curves of the ATP content of E. coli cell suspensions incubated in nutrient broth at various initial cell concentrations

Cells were incubated at the initial concentrations of $10^{1}(\diamond), 10^{2}(\bullet), 10^{3}(\square), 10^{4}(\mathbf{\Delta})$, and $10^{5}(\mathbf{\square}$ $\mathrm{CFU} / \mathrm{mL}$. Point $\mathrm{P}$ is described in the delay method section.

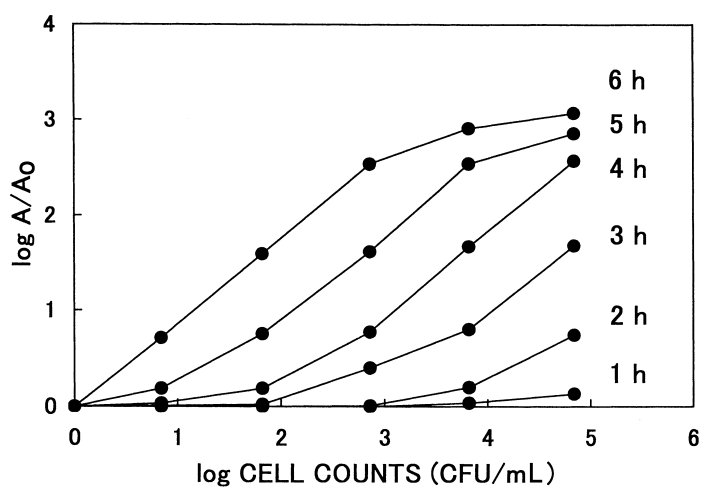

Fig. 2. The increase in the ATP contents of E. coli cell suspensions of various initial cell concentrations at incubation periods of 1 to 6 hours

The data of Fig. 1 at the vertical sections of 1 to 6 hours of incubation were analyzed for the initial cell concentrations. The hours shown in the figure are the incubation periods.

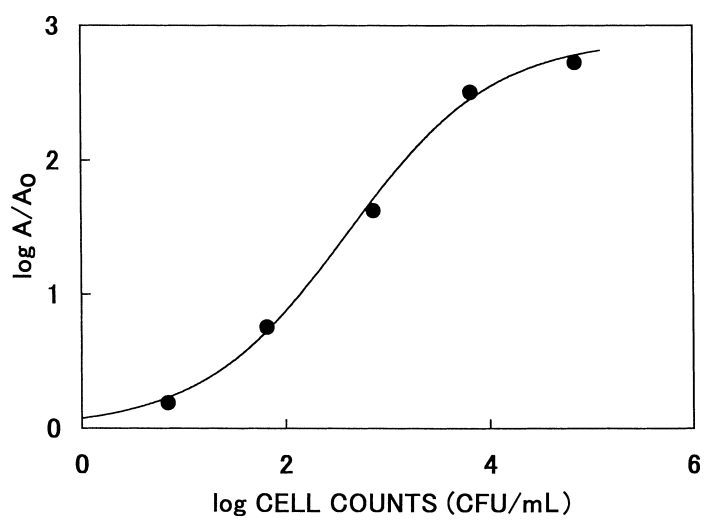

Fig. 3. Application of a logistic equation to the ATP increase in $E$. coli cell suspensions at 5-hour incubation

The data points are at the 5-hour incubation period in Fig. 2. The curve was fitted to the data with Eq. (1).

tions were too low to analyze (Fig. 2). On the other hand, the ratio at a low cell concentration was greater for the longer incubation period. The increase ratio with a longer incubation period could predict a smaller cell concentration of a sample (Fig. 2). However, a method with a short incubation period is preferable in terms of rapidity for practical use. In these circumstances, a 5-hour incubation was chosen for further work in this study. The plotted line at 5-hour incubation was sigmoidal and the data points were well described with a modified logistic equation (1) by Gibson et al. ${ }^{18)}$ (Fig. 3).

$$
R=a /(1+\exp (-b(X-c))
$$

Here $R$ and $X$ are the common logarithms of $A / A_{0}$ and the initial cell concentration $(\mathrm{CFU} / \mathrm{mL})$, respectively. exp is exponential, and $a, b$, and $c$ are coefficients. Values of $a, b$, and $c$ in Fig. 3 were 2.9, 1.4, and 2.6, respectively. It was considered that with this relationship, the initial cell concentration of a test suspension could be estimated from the value of $A / A_{0}$ at 5 -hour incubation.

The relationship between the increase ratio at 5-hour incubation and the initial cell concentration was studied for other food contaminating bacteria of Pseudomonas sp., S. aureus, B. subtilis, and Klebsiella sp. under the same experimental conditions as those of $E$. coli. The data points for those bacteria were also well described with Eq. (1) (Fig. 4). Values of the coefficients in the equation for the bacteria are shown in Table 1. The results suggested that the initial cell concentration of a test suspension of these bacteria could also be

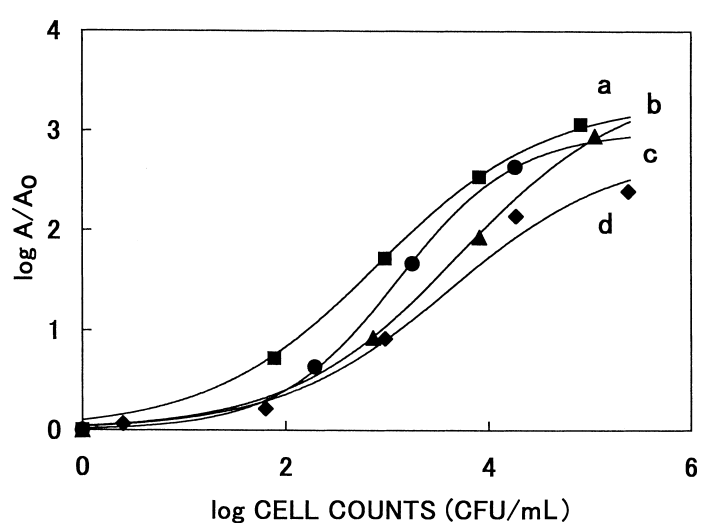

Fig. 4. The increase in the ATP contents of cell suspensions at 5-hour incubation for several species of bacteria

Symbols: - $\mathbf{\square}$, Kebsiella sp.; ๑, B. subtilis; $\mathbf{\Delta}$, S. aureus; $\$$, Pseudomonas sp. Curves are described with Eq. (1) for (a) Klebsiella sp., (b) S. aureus, (c) B. subtilis, and (d) Pseudomonas sp.

Table 1. Values of Coefficients of the Logistic Equation for Various Bacterial Species

\begin{tabular}{lccc}
\hline \hline \multicolumn{1}{c}{ Species } & $a$ & $b$ & $c$ \\
\hline Klebsiella sp. & 3.3 & 1.2 & 2.9 \\
Pseudomonas sp. & 2.8 & 1.2 & 3.6 \\
S. aureus & 3.5 & 1.2 & 3.7 \\
B. subtilis & 3.0 & 1.7 & 3.1 \\
\hline
\end{tabular}

$a, b$, and $c$ are the coefficients of Eq. (1). 
estimated using the end point method.

\section{Delay method}

The increase kinetics of ATP contents of $E$. coli cell suspensions shown in Fig. 1 was also analyzed with a delay method. Let us define the lag period, $L$ (hour), in the ATP increase curve as the period between two points. One point is the point at the initial time. The other point is the intersection of the linear regression line for the exponentially increasing period and a straight line passing through the point of the initial time, parallel to the horizontal axis. An example of this point at the concentration of $10^{1} \mathrm{CFU} / \mathrm{mL}$ is point $\mathrm{P}$ in Fig. 1. For this example, $L$ was 5.22 hours.

There was a highly linear relationship between the logarithm of the initial cell concentration, $X$, and the lag period, $L$, for $E$. coli in a range of $10^{1}-10^{5} \mathrm{CFU} / \mathrm{mL}$ (Fig. 5). The correlation coefficient was 0.999. The regression line was expressed as follows:

$$
L=d X+e
$$

where $d$ and $e$ are coefficients. Values of $d$ and $e$ for the

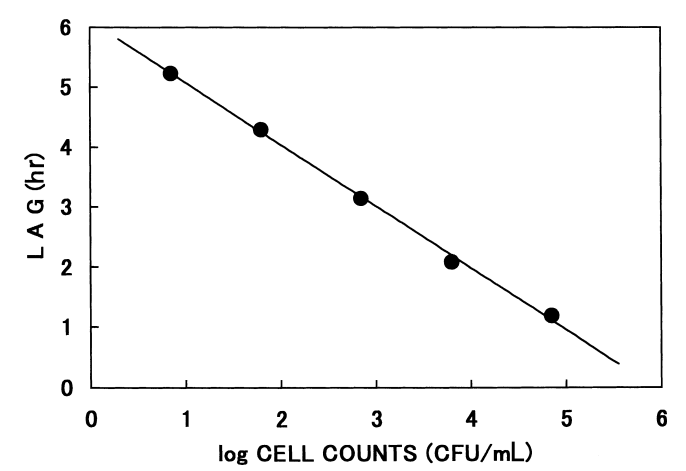

Fig. 5. The linear relationship between the lag period and the initial cell concentration of $E$. coli. The experimental data are taken from Fig. 1. The straight line is a linear regression line (Eq.(2)) of the data.

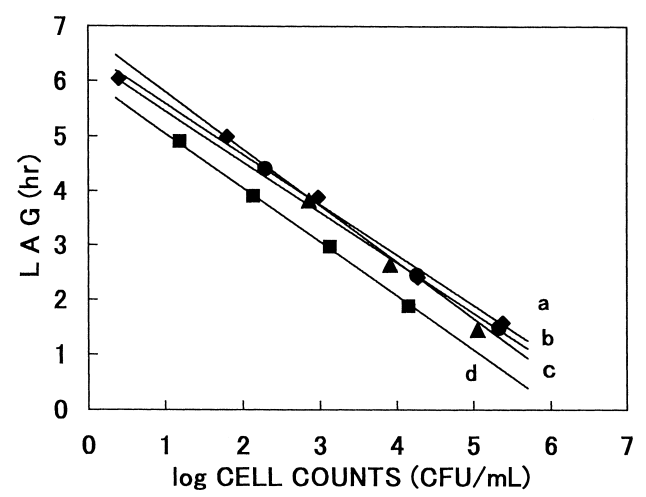

Fig. 6. The linear relationship between the lag period and the initial cell concentration for several species of bacteria

Symbols: - Klebsiella sp.; ๑, B. subtilis; $\mathbf{\Delta}$, S. aureus; $\bullet$ Pseudomonas sp. The straight lines are the regression lines for (a) Pseudomonas sp., (b) $S$. aureus, (c) B. subtilis, and (d) Klebsiella sp. The experimental data were the same data that were analyzed with the end point method.
Table 2. Values of Coefficients of the Linear Regression of Various Bacterial Species

\begin{tabular}{lll}
\hline \hline \multicolumn{1}{c}{ Species } & \multicolumn{1}{c}{$d$} & $e$ \\
\hline Klebsiella sp. & 0.990 & 6.04 \\
Pseudomonas sp. & 0.924 & 6.52 \\
S. aureus & 0.924 & 6.38 \\
B. subtilis & 1.04 & 6.84 \\
\hline
\end{tabular}

$d$ and $e$ are the coefficients of Eq. (2).

organism were -1.03 and 6.11 , respectively. It was speculated that, using this linear relationship, the initial cell concentration of a test suspension could be also estimated from the measured lag period.

The relationship between the lag period and the initial cell concentration was studied for the other bacteria tested above. The original data were the same as those analyzed using the end point method. A highly linear relationship was observed for all bacteria tested, with correlation coefficients of 0.999 (Fig. 6). Values of the coefficients in the equation for the bacteria are shown in Table 2. The results suggested that the initial cell concentration of a test suspension of these bacteria could also be estimated using the delay method.

\section{Discussion}

The new kinetic methods studied in this study should have several advantages for the estimation of bacterial concentration in samples.

(i) The incubation periods of the methods are much shorter than that of the conventional plate count method (48 hours). For example, the concentration of an $E$. coli cell suspension of $10^{3} \mathrm{CFU} / \mathrm{mL}$ could be estimated with the data of 5-hour incubation by the end point method (Fig. 3) and with the data up to 6-hour incubation by the delay method (Fig. 1). Moreover, it takes less than one minute to measure the ATP content of a sample with an ATP analyzer.

(ii) The detection limits of cell concentration by the methods are lower than that of the conventional method using an ATP analyzer. The detection limits for both the end point and delay methods in this study would be $10^{1} \mathrm{CFU} / \mathrm{mL}$ of E. coli cells (Figs. 3 and 5). The detection limit of the luminometer itself, estimated from the absolute ATP content of a sample, is about $10^{3-4} \mathrm{CFU} / \mathrm{mL}^{19), 20)}$. In this case, bacterial cells need to be suspended in purified water to measure the absolute bacterial cell concentrations, because some constituents of food samples such as salts quench the bioluminescence of food samples ${ }^{19)}$.

(iii) The kinetic methods did not need sophisticated apparatus. Miyamoto et al. ${ }^{21)}$ reported a method for bacterial cell counts with a photon-counting TV camera, which was based on firefly bioluminescence. There is also a commercially available system of microbial cell counting with a similar camera system (MicroStar ${ }^{\mathrm{TM}}$-RMDS, Millipore Corp.). However, such apparatus is expensive and might therefore be unsuitable to use for microbial cell counts in most food facto- 
ries. Moreover, test samples for such apparatus need to pass through membrane filters with a pore size of 0.45 or $0.22 \mu \mathrm{m}$. Compared to such apparatus, the ATP analyzer used in this study is just a conventional bioluminometer. Also, the kinetic methods studied here do not need any special process or treatment; only an incubation process is required.

(iv) Since the methods do not require filtration of a food sample, they could be applied to most commercial, processed foods that cannot pass through a conventional membrane filter with a pore size of 0.45 or $0.22 \mu \mathrm{m}$. In a preliminary study, we evaluated the methods using commercial foods inoculated with $S$. aureus or E. coli at various cell concentrations. Homogenates of the foods were not able to pass through conventional membrane filters. The methods gave good results for these food samples (data not shown).

Let us consider the characteristics of the two kinetic methods. The end point method was easy to measure and analyze, because it needed only the observed data at a single incubation time such as 5 hours, other than the initial ATP content. The delay method needed data points at several incubation times for analysis. Thus, measurement with the delay method is more laborious. However, the delay method might give more accurate predictions for the bacterial concentration of a sample than the end point method. This is because the variability of predicted cell concentrations by the delay method, which needs several data points, is considered to be less than that by the end point method. However, when the exact values of bacterial cell concentration for commercial foods are not required, the end point method would be practically useful for foods. It was thought that the end point method would be more suitable for practical application to foods than the delay method. For example, by introducing a threshold of the ATP increase ratio such as $\log A / A_{0}=0.3$, for food samples that are incubated for a given period, the end point method could easily be applied in routine assessment of bacterial contamination in food products. For the delay method, it would be useful to develop an automatic luminometer for sampling and measuring.

Some food products are contaminated by various kinds of bacteria. In this study we tested five representative bacterial species derived from foods. The two methods were successfully applied. Also, the values of the parameters of Eq. (1) and (2) were similar among the bacteria tested (Tables 1 and 2). Now we are evaluating the two methods by applying them to commercial foods. We will present the results in the near future.

\section{Acknowledgements}

The authors thank Prof. T. Tsuchido and Y. Haketa for valuable advice.

\section{References}

1) Anonymous, Standard methods of analysis in food safety regulation. Tokyo, Japan Food Hygiene Association, 1993.
2) Food and Drug Association, Bacteriological analytical manual, 8th Ed., Gaithersburg, AOAC International, 1995.

3) Goldschmidt, M. C., Fung, D. Y.C., Automated instrumentation for microbiological analysis. Food Technol., 3, 63-70, (1979).

4) Vanne, L., Karwoski, M., Karppinen, S., Sjoberg, A.-M., HACCP-based food quality control and rapid detection methods for microorganisms. Food Cont., 7, 263-276 (1996).

5) Bautista, D. A., Vaillancourt, J. P., Clarke, R. A., Renwick, S., Griffiths, M. W., Rapid assessment of the microbiological quality of poultry carcasses using ATP bioluminescence. J. Food Prot., 58, 551-554 (1995).

6) Cutter, C. N., Dorsa, W. J., Siragusa, G. R., A rapid microbial ATP bioluminescence assay for meat carcasses. Dairy, Food and Environ. Sanit., 16, 726-736 (1996).

7) LaRocco, K. A., Galligan, P., Littel, K. J., Spurgash, A., A rapid bioluminescent ATP method for determining yeast contamination in a carbonated beverage. Food Technol., 7, 49-52 (1985).

8) Littel, K. J., Pikelis, S., Spurgash, A., Bioluminescent ATP assay for rapid estimation of microbial numbers in fresh meat. J. Food Prot., 49, 18-22 (1986).

9) Miller, R., Galston, G., Rapid methods for the detection of yeast and lactobacillus by ATP bioluminescence. J. Inst. Brew., 95, 317-319 (1989).

10) Siragusa, G. R., Nawotka, K., Spilman, S. D., Contag, P. R., Contag, C. H., Real-time monitoring of Escherichia coli O157 : H7 adherence to beef carcass surface tissues with a bioluminescent reporter. Appl. Environ. Microbiol., 65, 1,738-1,745 (1999).

11) Sharpe, A. N., Woodrow, M. N., Jackson, A. K., Adenosine triphosphate levels in foods contaminated by bacteria. J. Appl. Bacteriol., 33, 758-767 (1970).

12) Williams, M. L. B., Limitations of the DuPont Luminescence Biometer in the microbiological analysis of foods. Can. Inst. Food Tech. J., 4, 187-189 (1971).

13) Hisa, K., Madokoro, H., Honma, S., An evaluation method of cleanness of meat processing instruments based on total ATP determination. J. Jpn. Food Sci. Tech., 45, 550-556, (1998).

14) Jay, J. M., "Modern Food Microbiology", 4th Ed., New York, Chapman and Hall, 1991, p. 136-139.

15) Kennedy, J. E., Oblinger, J. L., Application of bioluminescence to rapid determination of microbial levels in ground beef. J. Food Prot., 48, 334-340 (1985).

16) Stannard, C. J., Wood, J.M., The rapid estimation of microbial contamination of raw meat by measurement of adenosine triphosphate (ATP). J. Appl. Bacteriol., 55, 429-438 (1983).

17) Griffiths, M. W., Application of bioluminescence in the dairy industry. J. Dairy Sci., 76, 3118-3125 (1993).

18) Gibson, A. M., Bratchell, N., Roberts, T. A., The effect of sodium chloride and temperature on the rate and extent of growth of Clostridium botulinum type A in pasteurized pork slurry. J. Appl. Bacteriol., 62, 479-490 (1987).

19) Haketa, Y., Apparatus for bacterial cell counting by ATP measurement. J. Antibact. Antifung. Agents., 25, 457466 (1997)

20) Vaheri, A. et al.,ed., "Rapid methods and automation in microbiology and immunology", Berlin, Springer Verlag, 1991, p. 520-532.

21) Miyamoto, T., Kuramitsu, Y., Ookuma, A., Trevanich, S., Honjoh, K., Hatano, S., Rapid detection and counting of viable bacteria in vegetables and environmental water using a photon-counting TV camera. J. Food Prot., 61, 1,312-1,316 (1998). 